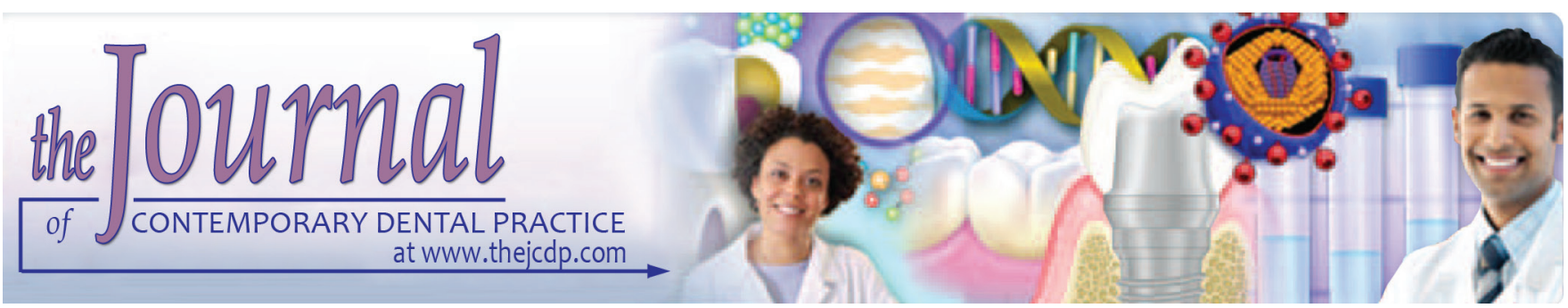

\title{
Stigma and Discrimination faced by HIV-infected Adults on Antiretroviral Therapy for more than 1 Year in Raichur Taluk, Karnataka, India
}

1Shrikanth Muralidharan, ${ }^{2}$ Arun Kumar Acharya, ${ }^{3}$ Shanthi Margabandu, ${ }^{4}$ Shalini Purushotaman

${ }^{5}$ Ranjit Kannan, ${ }^{6}$ Sangeeta Mahendrakar, ${ }^{7}$ Dinraj Kulkarni

\section{ABSTRACT}

Aim: The aim of this study was to evaluate the stress and discrimination faced by human immunodeficiency virus (HIV)-affected adult patients on antiretroviral therapy (ART) for more than 1 year.

Materials and methods: A cross-sectional study was carried out among 170 adults on ART, reporting to the ART center of the District Civil Hospital, for more than 1 year in Raichur Taluk, Karnataka, India. Convenience sampling technique was followed. Descriptive statistics was performed (Chi-square test) using Statistical Package for the Social Sciences version 16.0.

Results: A total of $156(91.8 \%)$ patients' families had knowledge about their seropositive status. Seventeen (10.9\%) HIV-positive patients reported of change in the attitude of their family members. The main reasons for not revealing the HIV status were the internalized stigma and fear of rejection. Women faced greater discrimination from family, friends, and neighbors than men.

${ }^{1}$ Department of Public Health Dentistry, M.A. Rangoonwala College of Dental Sciences \& Research Centre, Pune Maharashtra, India

${ }^{2,6}$ Department of Public Health Dentistry, Navodaya Dental College, Raichur, Karnataka, India

${ }^{3}$ Department of Public Health Dentistry, Mathrushri Ramabai Ambedkar Dental College and Hospital, Bengaluru, Karnataka India

${ }^{4}$ Department of Public Health Dentistry, Meenakshi Ammal Dental College, Chennai, Tamil Nadu, India

${ }^{5}$ Department of Public Health Dentistry, Asan Memorial Dental College and Hospital, Chengalpet, Tamil Nadu, India

${ }^{7}$ Department of Oral Pathology and Microbiology, M.A. Rangoonwala College of Dental Sciences \& Research Centre Pune, Maharashtra, India

Corresponding Author: Shrikanth Muralidharan, Department of Public Health Dentistry, M.A. Rangoonwala College of Dental Sciences \& Research Centre, Pune, Maharashtra, India, Phone: +918308008831, e-mail: shrikanthmuralidharan23@gmail.com
Conclusion: It is necessary to not undermine the effect of rejection due to HIV. It is the only infection that has so many associated social and psychological norms which we need to tend at the earnest. Till date, there is an existence of condescendence toward treatment approach.

Clinical significance: The presence of stigma and the fear of being discriminated could be a major hurdle in the rehabilitation of these patients into the mainstream society. Furthermore, it serves as an existing challenge to ascertain these individuals to achieve overall health.

Keywords: Discrimination, Family, Friends, Human immunodeficiency virus, Stigma, Workplace.

How to cite this article: Muralidharan S, Acharya AK, Margabandu S, Purushotaman S, Kannan R, Mahendrakar S, Kulkarni D. Stigma and Discrimination faced by HIV-infected Adults on Antiretroviral Therapy for more than 1 Year in Raichur Taluk, Karnataka, India. J Contemp Dent Pract 2017; 18(9):765-770.

\section{Source of support: Nil}

Conflict of interest: None

\section{INTRODUCTION}

Stigma is an essential aspect of the lives of people living with HIV / acquired immune deficiency syndrome (AIDS) (PLWHA). Although ART is available, there are no magic bullets against discrimination arising out of stigma that exists in both the urban as well as the rural setup across the world. It is a persistent and a pernicious problem, i.e., a hurdle to any steps taken for the betterment of the affected population. ${ }^{1}$ Logie et $\mathrm{al}^{2}$ have enumerated different types of stigmas that contribute to discrimination against HIV and further contribute to the spread of the infection.

- Symbolic

- Felt/normative stigma 
- Enacted stigma

- Internalized stigma.

According to Florom-Smith and De Santis, ${ }^{3} \mathrm{HIV}$ associated stigma results in a number of problems. Most of the studies related to stigma have concentrated on the African nations. Abrahams and Jewkes ${ }^{4}$ stated that there was perceived stigma among African women who faced gossips and insults. A meta-analyzed article by Katz et $\mathrm{al}^{5}$ highlights that HIV-associated stigma underlines the social relationships and its exacerbation on the economic impacts of HIV. Rahangdale et $\mathrm{al}^{6}$ reported about discrimination against women in rural areas of India due to their seropositive status from society, neighborhood, family, and by health-care professionals. Nambiar ${ }^{7}$ has stated in her article that the nongovernmental organizations were not willing to take up targeted interventions related to HIV and other special groups due to the fear of stigma associated with working for such a population. In India, stigma in such cases is fanned further due to lack of awareness, traditional beliefs, and a moralistic sexual tag. ${ }^{8}$ Stigma is a major barrier for the successful treatment of the PLWHA worldwide as highlighted by a number of studies. ${ }^{9-18}$ We report the first study related to stigma in the North Karnataka Region of India, which is one of the most underdeveloped areas of the state and has a high prevalence of HIV / AIDS.

\section{MATERIALS AND METHODS}

Ethical clearance was obtained from the Institutional Review Board of Navodaya Dental College, Raichur, India, before the start of the study. Permission was also obtained from the head of the ART center, Raichur. One hundred seventy individuals above 18 years of age on ART for more than 1 year and who gave a voluntary informed consent were included in the study.

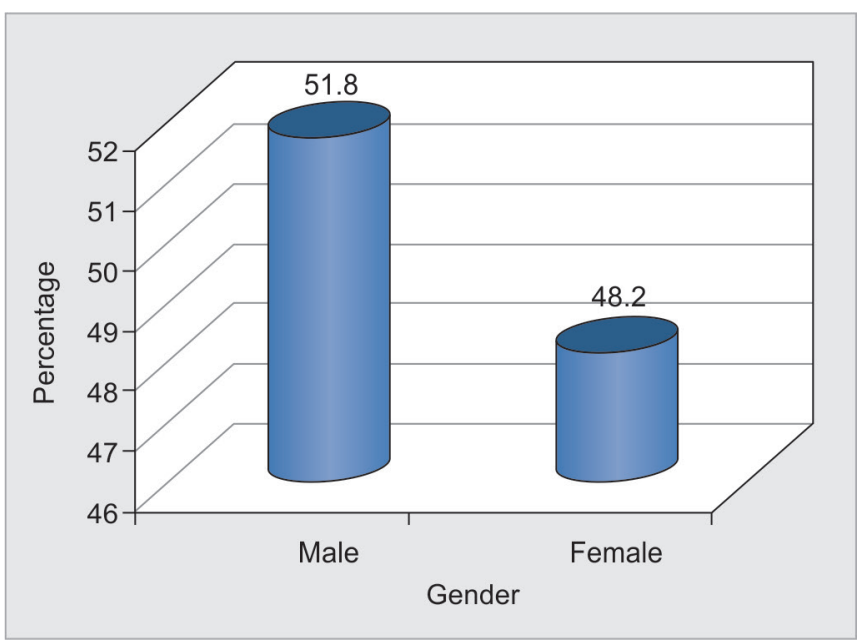

Graph 1: Distribution of the HIV-positive patients based on their gender
Convenience sampling was followed since it was difficult to obtain a sampling frame and go for a probability sampling technique due to confidentiality issues. The questions were pretested with a pilot study on 30 seropositive individuals. The time period of the study was 5 months (from December 2013 to April 2014). The participants were assured that their answers would not hinder their treatment at the center. No incentives in any form were provided to the people.

\section{RESULTS}

The study included $170 \mathrm{HIV}$-positive people from 19 to 60 years of age, average age of $37.17 \pm 8.21$ years, of which 88 (51.8\%) were males and $82(48.2 \%)$ were females (Graph 1). They came from the rural part of Raichur, and $95.3 \%$ of the participants belonged to the lower class. Only $3.05 \%$ were unmarried. Thirty-nine patients had visited the dentist before, of which $17(43.6 \%)$ were males and $22(56.4 \%)$ were females.

Forty-three $(25.3 \%)$ of the 170 participants isolated themselves to avoid any form of uncomfortable questions or comments by relocating to a distant village. Fifty-one $(30.0 \%)$ of the 170 participants reported of voluntarily avoiding functions and get-togethers, while older men reported staying indoors and not going to meet friends and relatives since long.

\section{Change in Attitude of Family Members against the HIV-positive Patients}

Among the 170 HIV-positive patients, 156 (91.8\%) patients' families had knowledge about their seropositive status and $14(8.2 \%)$ had yet not revealed their status to their family (Graph 2). One man (1.1\%) of the 88 , who was a physician, had not revealed his status to his wife before marriage, leading to his wife and two children becoming

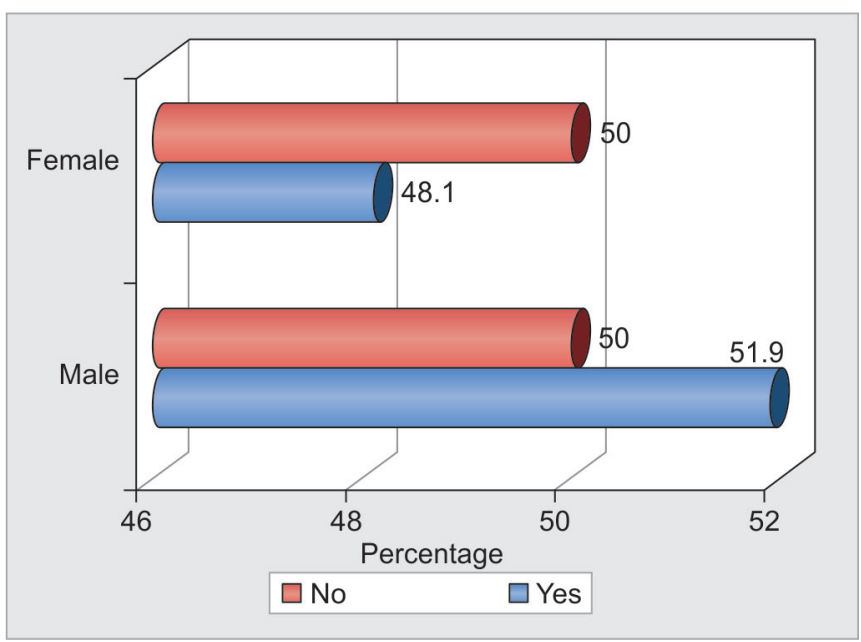

Graph 2: Gender-wise distribution of HIV-positive patients based on their family awareness about their HIV status 


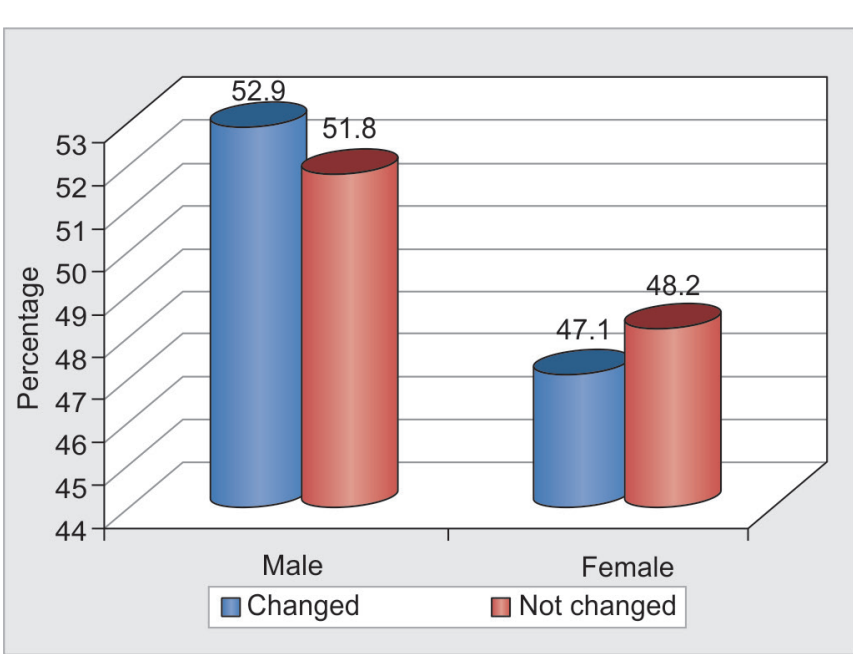

Graph 3: Gender-wise distribution of HIV-positive patients based on the change in the attitude of family members toward their status

HIV positive. One woman $(1.2 \%)$ out of the 82 reported suicidal attempts due to depression.

The attitude of 17 (10.9\%) of the 156 HIV-positive patients' family members had changed [8 (47.1\%) females and $9(52.9 \%)$ males] (Graph 3). There was no significant difference in the attitude of family members with respect to the gender of the participants $\left(\chi^{2}=0.019\right.$, $\mathrm{df}=1, \mathrm{p}=0.89$ ).

Out of these $17,2(11.7 \%)$ were not permitted to mingle with them as before, one each $(5.9 \%)$ was given separate isolated rooms and faced indifferent attitude, and 13 participants $(76.5 \%)$ faced discrimination in more than one form. There was no statistically significant difference between the male and female participants with respect to discrimination by their respective family members $\left(\chi^{2}=0.008, \mathrm{df}=1, \mathrm{p}=0.93\right)$.

Among the 8 women of the 17 whose family had knowledge about their seropositive status, 4 (50.0\%) reported that they were held responsible for the HIVpositive status of their spouses and $2(25.0 \%)$ of them were thrown out of the house, and their husbands had got married again. One woman reported being thrown out of the house with her children after the death of the spouse even though the family was highly educated and knew that she was not to be blamed and economically quite strong to support her. Although the married couples were happier and open about their status, those who were single faced the worst situation. A young unmarried participant had not revealed his status to any one as he was afraid of problems related to marriage and community neglect.

One woman $(7.1 \%)$ of the remaining 14 , who had not revealed her status, was associated with the education department. Although she was educated, she had a fear of mockery and losing her job. All the women covered their faces while traveling to the center to avoid recognition.

\section{Change in Attitude of Friends against the HIV-positive Patients}

Table 1 shows the gender-wise distribution of HIVpositive patients based on the knowledge of their friends about their HIV-positive status.

The main reasons for not revealing the HIV status were the internalized stigma and fear of rejection. Thirtyone $(18.2 \%)$ of the $170 \mathrm{had}$ revealed their status to their friends. Four (12.9\%) out of these 31, faced discrimination. One $(25.0 \%)$ participant said that it was no longer possible to mingle with friends as before. One $(25.0 \%)$ participant could neither mingle nor share food with friends as before, while two (50.0\%) faced all these along with a problem of refusal to stay in the same room (Graph 4).

\section{Change in Attitude of People at Workplace against the HIV-positive Patients}

Out of the 82 women involved in the study, 9 women $(11.0 \%)$ had revealed their HIV status at their workplace. One woman of the nine $(11.11 \%)$ reported of not being provided with water to drink at the workplace, four women $(44.4 \%)$ had lost work, and they were subjected to verbal abuse. Sixteen men (18.2\%) out of 88 had revealed their status at their workplace, but none reported of any

Table 1: Gender-wise distribution of HIV-positive patients based on the knowledge of their friends about their HIV-positive status

\begin{tabular}{llll}
\hline Friends knowledge & & & \\
about the HIV status & Male $n(\%)$ & Female $n(\%)$ & Total $n(\%)$ \\
\hline Yes & $17(54.8)$ & $14(45.2)$ & $31(100)$ \\
No & $71(51.1)$ & $68(48.9)$ & $139(100)$ \\
\hline Total & $88(51.8)$ & $82(48.2)$ & $170(100)$ \\
\hline
\end{tabular}

$\chi^{2}=0.032, d f=1, p=0.86$

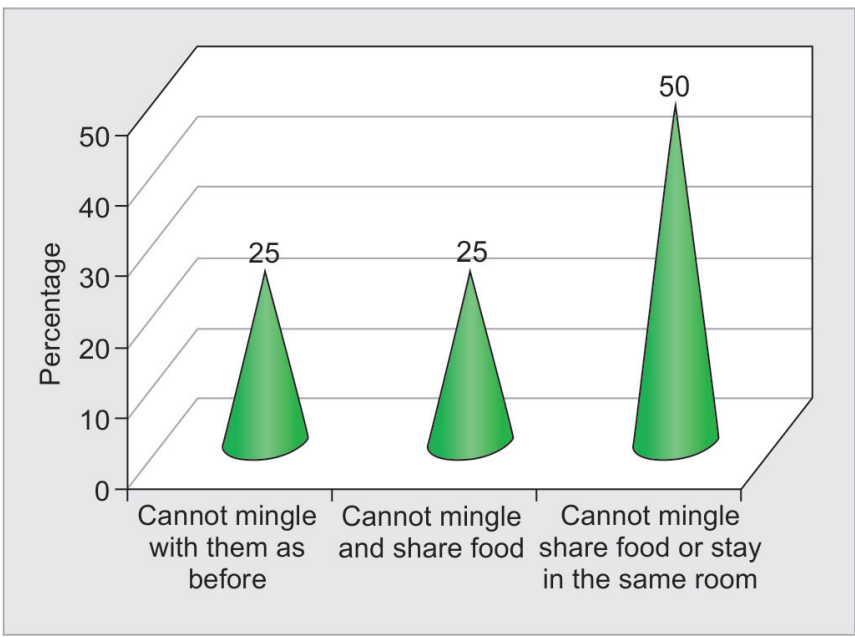

Graph 4: Distribution of HIV-positive patients based on the type of change in the attitude of their friends 
Table 2: Gender-wise distribution of HIV-positive patients depending on the change in the attitude of their workplace colleagues after revealing their HIV-positive status

\begin{tabular}{llll}
\hline $\begin{array}{l}\text { Workplace colleague } \\
\text { awareness }\end{array}$ & Male $n(\%)$ & Female $n(\%)$ & Total $n(\%)$ \\
\hline Changed & $00(0.0)$ & $4(100)$ & $4(100)$ \\
Not changed & $16(76.2)$ & $5(23.8)$ & $21(100)$ \\
\hline Total & $16(64.0)$ & $9(36.0)$ & $25(100)$ \\
\hline
\end{tabular}

$\chi^{2}=5.48, d f=1, p=0.01$

change in the attitude of their colleagues. No statistically significant difference was found between the males and the females with respect to the change in the attitude at their place of work $\left(\chi^{2}=1.23, \mathrm{df}=1, \mathrm{p}=0.20\right)$. Table 2 shows the gender-wise distribution of HIV-positive patients depending on the change in the attitude of their workplace colleagues after revealing their HIV-positive status, which was statistically significant.

Discrimination from dentists was reported by $3.52 \%$ (6 out of 170$)$ of participants.

\section{DISCUSSION}

Infection with HIV / AIDS is considered as a devastating global health problem posing severe challenges in lowand middle-income countries. There are a lot of challenges that the people suffering from HIV face (Fig. 1). It is easy to enumerate them but difficult to actually be in their shoes. These individuals irrespective of their background or the people among whom they stay are subjected to a number of psychological stresses. Human immunodeficiency virus is not only just a disease affecting the body but also the mind of the patients leading to depression, suicidal tendencies, and loss of interest to

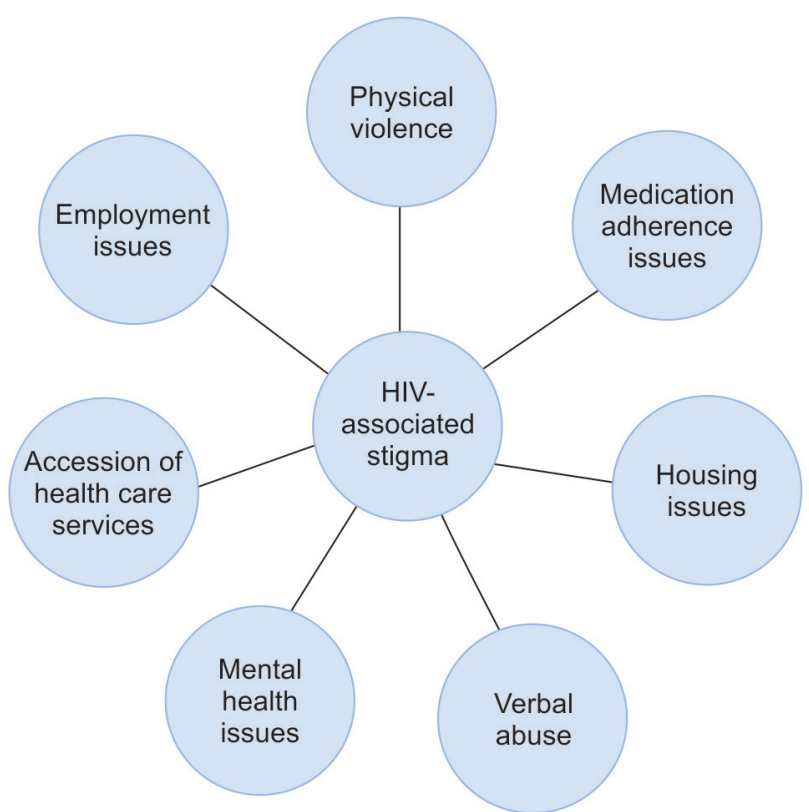

Fig. 1: The HIV associated stigma and related issues live a life that takes away the interest of the patients from self-care resulting in neglect and further complications. The present study participants reported of discrimination by family, friends, and at workplace in different forms. A few even reported of such behavior by dental practitioners. Our findings are consistent with that of the study in rural Bagalkot, India, ${ }_{14}^{14}$ though the participants faced less discrimination in this study due to the lack of disclosure. We found social discrimination as prevalent in our study similar to the study among the rural and tribal people of Maharashtra. ${ }^{19}$ There was no association of age with discrimination unlike the findings of a study among older US adults above 50 years who faced depression due to stigma. ${ }^{20}$ Less social support for people on ART was suggested by Pearson et al. ${ }^{21}$ Furthermore, the past studies have associated stigma with delay in seeking treatment. ${ }^{22}$ The people of Raichur faced lesser discrimination compared with the study population in Africa, ${ }^{23}$ where $23.8 \%$ faced discrimination form family/spouse, $18.8 \%$ were excluded from social gatherings, and $15.5 \%$ faced family activity exclusion. There was a great amount of internalized stigma in this study, which could be a prime reason for the nondisclosure of the participants, as suggested by Tsai et al. ${ }^{24}$ Since most of the individuals used avoidance as a coping mechanism, it could lead to a greater negative psychological impact. ${ }^{11,12}$ The social rejection faced by the participants in this study was in the form of not sharing food, water, or room. Such mentality existing in the HIV-free population was highlighted by others as well. ${ }^{9,16,19,25-28} \mathrm{~A}$ few participants reported of depression and one had a suicidal tendency, so HIV-associated discrimination could be a serious cause of depression. A study in Thailand showed that emotional and social support was inversely related to depression and directly related to stigma. ${ }^{29}$ Such an association was also suggested in different studies across the world. $15,17,21,22,30$ The fear of losing jobs, verbal abuse, and family and social rejection was main reasons for nondisclosure in the study population, same as other studies. ${ }^{8,31}$ According to Mbonu et $\mathrm{al}^{28}$ stigma and resultant depression could be a major cause for more risky behavior among the people. It is essential to deal with the internal stigma since it affects the individual's adherence to ART, quality of life, and their social experiences directly. ${ }^{13,17,18,32}$

Steward et $\mathrm{al}^{33}$ found that HIV-infected people on treatment who experience discrimination and who believe stigma against them are more likely to report symptoms of depression. In addition, experiences of discrimination and hearing stories about others being mistreated because of HIV correlate with the perception that stigma is more prevalent in the local community. These perceptions are in turn associated with efforts to avoid disclosure of one's HIV status and with reports 
of depressive symptoms. It is not necessary for stigma among local community members to change before a patient on treatment can experience improvements in mental health. By challenging HIV-positive individuals' own hostile attitudes toward the disease, it may be possible to improve their overall psychological health.

Patients try their best to conceal their infection status from their near and dear ones because of the fear of stigma. People fear that they might be ostracized from the society if their infection status is revealed. ${ }^{34}$ This adds to the existing debilitating state of these patients and pushes them to substance abuse. ${ }^{15}$ The stigma associated with this was large even in the educational faculty. The assistant intern accompanying the research worker was discouraged by his colleagues stating that he may catch HIV. A few patients who were a part of this study had walked out before seeking treatment from the dental college to which they were referred due to the indifferent attitude of the postgraduate students assigned to these patients. The past Indian studies in the metropolitan cities of Mumbai and Bengaluru have reported the prevalence of such tendency among the health-care professionals. ${ }^{10}$ Tzemis et $\mathrm{al}^{18}$ suggest education as a means to remove this stigma. They found that higher education was associated with low stigma among Canadian population. As Azodo et $\mathrm{al}^{35}$ put it correctly, public perception of the HIV epidemic has culminated in heightened and persistent public anxiety. This anxiety is attributed to the high mortality rate of AIDS, and it is a fact that there is, to date, no proven vaccine or cure for this mentality.

\section{Limitations}

- We used a convenience sampling, and hence the data cannot be extrapolated to all the population

- Since India, especially rural India, is still lacking in many fronts, the same mentality cannot be held true for urban population of another place

- There is always a chance of responders bias in this study as we relied wholly on the answers of the participants, some may have overrated or underrated the experiences, and also due to the fact that there were no closed-door counseling rooms for the people

- Discrimination by the health-care professionals could be also underreported by the participants.

\section{CONCLUSION}

This study highlights the presence of HIV-associated stigma in Raichur. It is essential to understand that, since this place is one of the most backward regions, there is a scope for a lot of health promotion to be carried out. Health-care professionals have been also neglecting these patients for long, and hence their adherence and faith on the faculty have been on a slow but definite decline. Priority has always been treating the infections and a CD4 count of HIV patients, but the psychological impact has never been an area of concern in the Indian setup. It is necessary to not undermine the effect of rejection due to HIV. It is the only infection that has so many associated social and psychological norms which we need to tend at the earnest. Till date, there is an existence of condescendence toward treatment approach. Counseling at any center in India hardly is of a quality type, and main focus is on achieving numbers on paper. Some self-reflection on the part of the National AIDS Control Organization, National AIDS Research Institute, and the Health Ministry of India is essential. As health-care professionals, we too are failing the patients in the forefront. No special training or lectures are given to students related to the psychological aspects of handling a special group of patients. A lot needs to be done.

\section{Public Health Significance}

The comprehensive treatment plan for any HIV-associated group should also involve community participation as highlighted in this study. There is a need for a more humanitarian approach rather than a business approach toward these people. Words can do wonders that should always be remembered. Furthermore, the role of the future health professionals needs to be tailor made for an upliftment of the dwindling stature of the profession.

\section{REFERENCES}

1. Mahajan AP, Sayles JN, Patel VA, Remien RH, Ortiz D, Szekeres G,Stigma in the HIV / AIDS epidemic: a review of the literature and recommendations for the way forward. AIDS 2008 Aug;22(Suppl 2):67-79.

2. Logie CH, James L, Tharao W, Loutfy MR. HIV, gender, race, sexual orientation, and sex work: a qualitative study of intersectional stigma experienced by HIV-positive women in Ontario, Canada. PLoS Med 2011 Nov;8(11):1-12.

3. Florom-Smith AL, De Santis JP. Exploring the concept of HIVrelated stigma. Nurs Forum 2012 Jul-Sep;47(3):153-165.

4. Abrahams N, Jewkes R. Managing and resisting stigma: a qualitative study among people living with HIV in South Africa. J Int AIDS Soc 2012 Aug;15(2):1-11.

5. Katz IT, Ryu AE, Onuegbu AG, Psaros C, Weiser SD, Bangsberg DR, Tsai AC. Impact of HIV-related stigma on treatment adherence: systemic review and meta-analysis. J Int AIDS Soc 2013 Nov;16(2):1-22.

6. Rahangdale L, Banandur P, Sreenivas A, Turan J, Washington R, Cohen CR. Stigma as experienced by women accessing prevention of parent to child transmission of HIV services in Karnataka, India. AIDS Care 2010 Jul;22(7):836-842.

7. Nambiar D. HIV-related stigma and NGO-isolation in India: an historic-empirical analysis. Sociol Health Illn 2012 Jun;34(5):714-729.

8. Nebhinani N, Mattoo SK, Wanchu A. HIV stigma and specified correlates in North India. Indian J Psychol Med 2012 Oct-Dec;34(4):324-331. 
9. Earnshaw VA, Bogart LM, Dovidio JF, Williams DR. Stigma and racial/ethical disparities: moving toward resilience. Am Psychol 2013 May-Jun;68(4):225-236.

10. Ekstrand M, Ramakrishna J, Bharat S, Heylen E. Prevalence and drivers of HIV stigma among providers in urban India: implications for interventions. J Int AIDS Soc 2013 Nov;16(3):1-12.

11. Varni SE, Miller CT, McCuin T, Solomon SE. Disengagement and engagement coping with HIV/AIDS stigma and psychological well-being of people with HIV / AIDS. J Soc Clinc Psychol 2012 Feb;31(2):123-150.

12. Varni SE, Miller CT, Solomon SE. Sexual behaviour as a function of stigma and coping with stigma among people with HIV/AIDS in rural New England. AIDS Behav 2012 Nov;16(8):2330-2339.

13. Martinez J, Harper G, Carleton RA, Hosek S, Bojan K, Glum G, Ellen J, Adolescent Medicine Trials Network. The impact of stigma on medication adherence among HIVpositive adolescents and young adult females and the moderating effects of coping and satisfaction with health care. AIDS Patient Care STDS 2012 Feb;26(2):108-115.

14. Nyamati A, Ekstrand M, Zolt-Gilburne J, Ganguly K, Sinha S, Ramakrishnan P, Suresh P, Marfisee M, Leake B. Correlates of stigma among rural Indian women living with HIV / AIDS. AIDS Behav 2013 Jan;17(1):329-339.

15. Piptian EV, Kalichman SC, Eaton LA, Cain D, Sikkema KJ, Skinner D, Watt MH, Pieterse D. AIDS-related stigma, HIV testing and transmission risk among patrons of informal drinking places in Cape Town, South Africa. Ann Behav Med 2012 Jun;43(3):362-371.

16. Hasan MT, Nath SR, Khan NS, Akran O, Gomes TM, Rashid SF. Internalized HIV / AIDS-related stigma in a sample of HIV-positive people in Bangladesh. J Health Popul Nutr 2012 Mar;30(1):22-30.

17. Nattabi B, Li J, Thompson SC, Orach CG, Earnest J. Between a rock and a hard place: stigma and the desire to have children among people living with HIV in Northern Uganda. J Int AIDS Soc 2012 May;15(2):1-11.

18. Tzemis D, Forrest JI, Puskas CM, Zhang W, Orchard TR, Palmer AK, Mclnnes CW, Fernades KA, Montaner JSG, Hogg RS. Identifying self-perceived HIV-related stigma in a population accessing antiretroviral therapy. AIDS Care 2013 Jun;25(1):1-13.

19. Vlassoff C, Weiss MG, Rao S, Ali F, Prentice T. HIV-related stigma in rural and tribal communities of Maharashtra, India. J Health Popul Nutr 2012 Dec;30(4):394-403.

20. Grov C, Golub SA, Parsons JT, Nrennan M, Karpiak SE. Loneliness and HIV-related stigma explain depression among older HIV-positive adults. AIDS Care 2010 May;22(5):630-639.

21. Pearson CR, Micek MA, Pfeiffer MJ, Montoya P, Matediane E, Jonasse T, Cunguara A, Rao D, Gloyd SS. One year after ART initiation: psychological factors associated with stigma among HIV-positive mozambicans. AIDS Behav 2009 Dec;13(6):1189-1196.

22. Steward WT, BharatS, Ramakrishnan J, Heylen E, Ekstrand ML. Stigma is associated with delays in seeking care among
HIV-infected people in India. J Int Assoc Provid AIDS Care 2013 Mar-Apr;12(2):103-109.

23. Dos Santos MM, Kruger P, Mellors SE, Wolvaardt G, van der Ryst E. An exploratory survey measuring stigma and discrimination experienced by people living with HIV / AIDS in South Africa: the people living with HIV stigma index. BMC Public Health 2014 Jan;14:3-13.

24. Tsai AC, Bangsberg DR, Kegeles SM, Katz IT, Haberer JE, Muzoora C, Kumbakumba E, Hunt PW, Martin JN, Weiser SD. Internalized stigma, social distance, and disclosure of HIV seropositivity in rural Uganda. Ann Behav Med 2013 Dec;46(3): $1-17$.

25. Ekstarnd ML, Bharat S, Ramakrishna J, Heylen E. Blame, symbolic stigma and HIV misconceptions are associated with support for coercive measures in Urban India. AIDS Behav 2012 Apr;16(3):700-710.

26. Visser MJ, Makin JD, Vandormael A, Sikkema KJ, Forsyth BW. HIV / AIDS stigma in a South African community. AIDS Care 2009 Feb;21(2):197-206.

27. Gonzalez A, Mille CT, Solomon SC, Bunn JY, Cassidy DG. Size matters: community size, HIV stigma and gender differences. AIDS Behav 2009 Dec;13(6):1205-1212.

28. Mbonu NC, van der Borne B, De Vries NK. Stigma of people with HIV/AIDS in Sub-Saharan Africa: a literature review. J Trop Med 2009 Jun;2009:14.

29. Li L, Lee SJ, Thammawijaya P, Jiraphongsa C, RotheramBorus MJ. Stigma, social support and depression among people living with HIV in Thailand. AIDS Care 2009 Aug;21(8):1007-1013.

30. Sayles JN, Ryan GW, Silver JS, Sarkisian CA, Cunningham WE. Experiences of social stigma and implications for healthcare among a diverse population of HIV positive adults. J Urban Health 2007 Nov;84(6):814-828.

31. Li X, Huang L, Wang H, Fennie KP, He G, Williams AB. Stigma mediates the relationship between self-efficacy, medication adherence and quality of life among people living with HIV/AIDS in China. AIDS Patient Care STDS 2011 Nov;25(11):665-671.

32. RaoD, Chen WT, Pearson CR, SimoniJK, Fredriksen-Goldsen K, Nelson K, Zhao H, Zhang F. Social support mediates the relationship between HIV stigma and depression/quality of life among people living with HIV in Beijing, China. Int J STD AIDS 2012 Jul;23(7):481-484.

33. Steward WT, Chandy S, Singh G, Panicker SJ, Osmand TA, Heylen E, Ekstrand ML. Depression is not an inevitable outcome of disclosure avoidance: HIV stigma and mental health in a cohort of HIV infected individuals from Southern India. Psychol Health Med 2011 Jan;16(1):74-85.

34. Anish TS, Vijaykumar K, Simi SM. Determinants of rapid progression to immunodeficiency syndrome among people infected with human immunodeficiency virus, Kerala, India. Indian J Sex Transm Dis AIDS 2011 Jan;32(1):23-29.

35. Azodo CC, Ehizele AO, Umoh A, Ogbebor G. Preventing HIV transmission in Nigeria: role of the dentists. Malays J Med Sci 2010 Apr-Jun;17(2):10-17. 